\title{
Una Mirada al Terapeuta en el Proceso de Psicoterapia
}

\author{
A look at the therapist in the Psychotherapy Process
}

Andrea V. Hernández Ruíz ${ }^{a}$, María L. Escamilla Gutiérrez ${ }^{b}$

\begin{abstract}
:
The objective of this essay is to explain the role of the therapist in the psychotherapy process. It briefly addresses some elements of the cognitive behavioural paradigm in psychology, as well as commenting on the necessary skills and aptitudes that are required for good clinical practice, also mentioning that they are skills that are learned through practice and perseverance, while still it aside of course the frequent mistakes of the therapist, and the importance of recognizing them.
\end{abstract}

\section{Keywords:}

Therapist, psychotherapy, skills, cognitive behavioral paradigm

\section{Resumen:}

El objetivo de este ensayo es explicar el rol del terapeuta en el proceso de psicoterapia. Se aborda brevemente algunos elementos del paradigma cognitivo conductual en psicología, así como comentar las habilidades y aptitudes necesarias que se requieren para una buena praxis clínica, mencionando además de que son habilidades que se aprenden a través de la práctica y la constancia, no dejando de lado por supuesto los errores frecuentes del terapeuta, y la importancia de reconocerlos.

\section{Palabras Clave:}

Terapeuta, psicoterapia, habilidades, paradigma cognitivo conductual

\section{Introducción}

Para la psicología fue complicado delimitar su campo de estudio en un mundo, donde todo el tiempo existen relaciones humanas complejas y procesuales, interaccionismo simbólico, intercambios, emociones, pensamientos, una mente, un cuerpo, y además, una gran duda de cómo lograr alcanzar su comprensión total y dimensional, debido a esto nacen los distintos paradigmas, modelos y teorías que permiten explicar cada uno en su diversidad la forma en cómo comprender el comportamiento humano y sus diferentes partes. Una de esas nuevas visiones, surgió hace ya más de medio siglo siendo éste en sus inicios un nuevo modelo de pensamiento, Ilamado paradigma o Terapia Cognitivo Conductual (TCC), se abrió un campo de aplicación importante para la psicología y sus métodos de práctica en sus diferentes conjugaciones, parte de esto es el desarrollo de la psicoterapia, lo que la hace ser todavía una extensión de las utilidades de la psicología, aunque solo es una pequeña parte del rompecabezas. Cabe mencionar entonces el papel del terapeuta, reconociéndolo, así como el aplicador del modelo cognitivo conductual, en tan solo una manera de definirlo. Surge la pregunta sobre si a través de toda la evolución que ha tenido la psicología, surgiendo de solo una corriente derivada de la filosofía, hasta ahora en la actualidad que es vista como proto-ciencia, cultivando sus enfoques y modelos para la comprensión del comportamiento, teniendo aplicadores de la teoría y consumadores de la práctica. Así entonces, se analizarán las habilidades que debe tener el terapeuta, qué lo hace un buen terapeuta (aplicador) de toda la corriente psicológica en su derivación clínica, y cómo es que llega a formarse como tal.

\footnotetext{
a Autor de Correspondencia, Universidad Autónoma del Estado de Hidalgo, Instituto de Ciencia de la Salud, Área Académica de Psicología, https://orcid.org/0000-0002-8933-5434, Email: avanessahruiz@gmail.com

${ }^{\mathrm{b}}$ Universidad Autónoma del Estado de Hidalgo, Instituto de Ciencia de la Salud, Área Académica de Psicología, https://orcid.org/0000-00026318-4519, Email: maria_escamilla@uaeh.edu.mx
} 


\section{Desarrollo}

Para entender de qué se habla cuando se menciona el concepto de terapeuta es fundamental comprender el concepto de Psicoterapia. Mahoney propone que es un vínculo o relación entre un profesional de apoyo y un individuo o grupo que actúan como clientes, dicha relación es de naturaleza humana y potencializa a un buen desarrollo psicológico, generando entre sus partes una alianza estable y de cuidado, por lo que es fundamental continuar con un enfoque que permita analizar dicho concepto como <<piedra angular $>>$ de la práctica clínica en psicología [1]. Así mismo, la psicoterapia se puede percibir como una relación cuyo propósito es la noción del saber de la consciencia, sin embargo, esa conceptualización no permite elucidar el quehacer básico del terapeuta, entonces así, cuando se modifica la definición del concepto de psicoterapia se modifican a su vez y de manera casi automática, los criterios de la distinción para ser un buen terapeuta ${ }^{[2]}$. La TCC se define como un ejercicio psicológico que emana principalmente de las teorías psicológicas del aprendizaje, tiene por objetivo lograr cambios de comportamiento, disminuye o elimina conductas desadaptativas y aumenta las adaptativas, abarca también elementos cognitivos, fisiológicos y emocionales [3]. En un artículo se explica que el terapeuta no nace, se hace ¿qué sucede con esta aseveración? orilla a pensar en los procesos de aprendizaje por los cuales tiene que pasar el terapeuta clínico para efectuar con validez sus prácticas psicológicas siendo estas de carácter profesional y como ya se dijo: adquiridas ${ }^{[2]}$. Promueve la idea de echar un vistazo en esas construcciones donde usualmente no se llega a mirar en esta relación y proceso actual <<bilateral $>>$, es decir, en el terapeuta, no dejando de lado, el papel preponderante del cliente ni su validez en la relación ${ }^{[4]}$. Las bases para la consideración de las habilidades y aptitudes del buen terapeuta son mencionadas por instituciones como la American Psychology Association (APA), que a través de la investigación científica de primer orden fundamenta y coacciona ante esto, manifestando premisas de funcionalidad en este proceso que si bien en sus inicios se consideraba de mayor peso al cliente en el progreso psicoterapéutico solo fue por sus inicios en lo psicodinámico ya a mediados del siglo veinte, se le dio el mismo peso al terapeuta, estando de acuerdo en esto un pionero de la psicología, Jung ${ }^{[2]}$.

Algunas corrientes mencionan que la importancia del inicio-desarrollo-y-proceso recae en el cliente, otros en la alianza terapéutica, se hace mención acerca del vínculo existente entre el terapeuta y el cliente y su función al momento de formar y seguir las partes y objetivos terapéuticos del tratamiento, cabe mencionar que el concepto de alianza terapéutica tiene sus orígenes en el campo psicoanalítico, que si bien no es el ortodoxo, hace más referencia a una especie de acuerdo, y que años después se modifica esta conceptualización en el paradigma cognitivo conductual ${ }^{[5]}$. En consecuencia a través del enfoque Cognitivo Conductual define los puntos del buen terapeuta, entre los que destacan el empirismo colaborativo que hace referencia a un intercambio entre los participantes del proceso de terapia (el terapeuta y el paciente), se mencionan dichas cualidades que debe de poseer como terapeuta para ejercer de manera profesional y ética, favoreciendo y optimizando el mismo proceso, entre estas cualidades destacan: el dialogo y cuestionamientos socráticos, las formas y técnicas de intervención, la colaboración, las formas de abrir una sesión, de mantener el foco de atención en el problema durante la sesión, las practicas aplicadas al fenómeno y el cierre de sesión, mencionando incluso la culminación del proceso psicoterapéutico, entre otros elementos, lo que lleva a reconsiderar que cada una de las aptitudes, actitudes y habilidades que se le solicita ejercer al terapeuta en la praxis, se pueden aprender y reaprender, confirmando así, que un terapeuta se hace, no nace, y que por ello es de relevancia practicar en el campo todas estas cualidades de manera consistente y a través del tiempo, es decir, nunca se deja de aprender cómo ser un buen terapeuta, hay que adaptase a las necesidades de la contemporaneidad ${ }^{[6]}$.

Entre las características del buen terapeuta se encuentran la escucha activa, la empatía, la aceptación incondicional y la autenticidad, solo como actitudes básicas, es decir, de inicio. Sin embargo, si se requiriera que el terapeuta favoreciera aún más dicha relación, necesita ser cordial, competente, tener e inspirar confianza, atracción, y cierto grado de directividad, todas estas conceptualizaciones implicando todo un camino y andar para la persona que requiere ese conocimiento, denotando su esfuerzo y aplicación al momento de la adquisición total y no parcial de cada elemento de la información. Un ejemplo del porqué es necesaria la práctica de estas habilidades y aptitudes, es visualizar realmente cuantas veces se es empático al día, o incondicional con la gente que no se conoce, si con los allegados a uno mismo los momentos de escucha activa, la confianza y el grado de aceptación se da de manera compleja, paulatina y en ocasiones hasta renuente, es lógico pensar entonces que con desconocidos estas habilidades no emerjan de repente, incluso es dificultoso imaginar que uno puede ser un buen terapeuta todo el tiempo y con todos los que conoce sin necesidad de practicar, aprender y mantener estas habilidades ${ }^{[7]}$. 
En esta diada de cliente-terapeuta se busca el mayor beneficio para el cliente, de manera que él pueda adquirir enseñanzas significativas ${ }^{[8]}$. Pero qué hace al terapeuta ser el mejor terapeuta sino son también sus motivaciones por ayudar al otro y adquirir un aprendizaje en el proceso, el terapeuta merece cierta atención en él mismo, evitando proyecciones en su paciente y haciendo a su vez, una intervención terapéutica más enriquecedora ${ }^{[9]}$. Se reconoce así que es necesaria la validación de la práctica a través de un método fiable, pero también se sabe que no se debe dejar de lado la relación interpersonal de la relación profesional ${ }^{[10]}$. Es necesario identificarse como seres completamente humanos, en este reconocimiento se vinculan los procesos que se deben aprender como buenos terapeutas. La gente no nace siendo empática, o con el saber de la escucha activa, ni mucho menos siendo incondicional, en muchas ocasiones, ni siquiera es fácil aceptarse a uno mismo como para poder aceptar totalmente a "un otro" ${ }^{[11]}$.

En tal caso la psicoterapia es todo un proceso que implica un desenvolvimiento de diversas habilidades y aptitudes que como ya se mencionó, debe poseer el terapeuta. Hace a éste un eje fundamental de dicho proceso terapéutico además de permitir una visualización de los avances del aprendizaje riguroso al que cada terapeuta es sometido para poder alcanzar la meta de ser "bueno" en su praxis ${ }^{[8]}$.

Hasta el momento se han mencionado las cualidades del terapeuta, sin embargo, para comprender un fenómeno de manera integral se tienen que observar su contraparte, conocer que conforma a un mal terapeuta, se dice que un buen terapeuta inicia con el entendimiento del conocimiento teórico básico que culmina en la práctica clínica, sin embargo, realmente como en toda rama y campo de aplicación existe gente que comete errores, $<<$ mayormente son novatos $>>$, es necesario conocer dichos desaciertos y saber que existen ya que así se hace menos el sesgo de conocimiento en esta mirada del terapeuta e incluso ayuda a prevenir la iatrogenia. Entre los errores que se han encontrado frecuentemente, se hayan los vinculados a creencias y actitudes de los terapeutas, permitiendo un sesgo en la recolección de información y en el proceso, así como errores de tipo relacionales en los que al ser los primeros inicios en la práctica, se suele ser demasiado rígido y no mostrar espontaneidad con el cliente, así como usualmente ocurre, apresurarse en el tratamiento acelerando el ritmo del paciente y de nuevo obstaculizando la terapia, existe también poca escucha y empatía, donde se recae en la focalización de temas durante la entrevista inicial que pueden ser irrelevantes, y no se manejan de manera significativa como forma de exploración sobre los verdaderos síntomas del paciente y no hay un control del terapeuta en la sesión [12].

\section{Conclusión}

La psicología ante la necesidad de modelos y paradigmas integrales y dimensionales que dieran una nueva visión del variante y complejo comportamiento humano, permite la adquisición de diferentes modelos teóricos explicativos, en los que se encuentra el cognitivo conductual, del que se desprende a su vez, la forma de delimitar una buena aplicación de la psicología en el proceso psicoterapéutico, y que se reconoce que en la forma de conceptualizar la psicoterapia, se denota y define también el proceso, que tiene por elementos al terapeuta y al cliente, ambos concebidos en la actualidad con la misma importancia y como elementos activos, existiendo también corrientes que le otorgan mayor peso a alguno de los componentes del proceso terapéutico, sin embargo, el enfoque cognitivo conductual permite hablar de un intercambio más que de un acuerdo o una responsabilidad única e inamovible entre las piezas que la conforman, y se prefiere hablar por consiguiente de bilateralidad. Además, mediante organizaciones internacionales se llegan a los acuerdos de las actitudes, aptitudes y funciones que tiene a su cargo el terapeuta para un óptimo desempeño en su praxis clínica, y que como se mencionó, se requiere de aplicar los conocimientos porque como en todo fenómeno humano, existe más de una sola visión de realidad, es decir que también existen errores que puede cometer el terapeuta en su profesión, a lo que se alude mayormente a la inexperiencia del inicio y los neófitos de la psicoterapia, y una de las formas de prevenir la mala praxis y mejorar, es reconocer ambas partes del aplicador (terapeuta) en este proceso de la psicología clínica.

\section{Referencias}

[1] Liria AF, Vega BR. La práctica de la Psicoterapia. Descleé de Brouweer; 2001.

[2] Campagne DM. El terapeuta no nace, se hace. AEN. 2014; 34:75-95.

[3] Ángeles MA, Díaz I, Villalobos A. Manual de Técnicas de Intervención Cognitivo Conductuales. Bilbao: Descleé de Brouweer. 2012

[4] Vargas MG. Concepto de psicoterapia en psicología clínica. Rev. Psicol. Univ. Antioquia. 2010; 2: 19-32.

[5] González NA. La alianza terapéutica. Clínica y Salud. 2005; 16: 9-29.

[6] Okamoto A, Dobson K, Dattilio F., Kazantzis N. The therapeutic relationship in Cognitive-Behavioral Therapy: Essential Features and Common Challenges. Practice Innovations. 2019; 4: 112-123.

[7] Bados A, García, E. Habilidades terapéuticas. Barcelona: Universidad de Barcelona; 2011.

[8] Szmulewicz T. La persona del terapeuta: eje fundamental de todo proceso terapéutico. Rev Chil Neuro-Psiquia. 2013; 51: 61-69.

[9] Borja G. La locura lo cura: Un manifiesto terapéutico. 5ta ed. Barcelona: Ediciones la llave; 2011. 
Publicación semestral, Educación y Salud Boletín Científico Instituto de Ciencias de la Salud Universidad Autónoma del Estado de Hidalgo, Vol. 8, No. 16 (2020) 58-61

[10] Bernardi R, Defey D, Garbarino A, Tutté, JC, Villalba L. Guía clínica para la psicoterapia. Rev Psiquiatr Urug. 2004; 68: 99-146.

[11] Yalom ID. El don de la terapia. 2da ed. España: Emecé; 2003.

[12] Herrera P, Veliz CAA. Errores y dificultades comunes en terapeutas novatos. Revista Argentina de Clínica Psicológica. 2018; 27: 5-13. 